\title{
José Antonio Pimenta Bueno, Bandeirante do Direito Brasileiro*.
}

\author{
Cesar Salgado
}

Tenho para mim, com a venia dos doutos, que aquela sentença do Genesis - "memento, homo, quia pulvis es et in pulverem reverteris."... - não deve ser entendida "ad litteram". Porque, se em verdade, a vida do homem se consumisse entre duas parcelas de pó, razão não haveria para o ato da criação.

$\mathrm{E}$, se é certo que o homem, segundo a legenda bíblica, foi feito de barro, certo é também que ele foi criado "à imagem e semelhança do Criador." $E$ está ainda escrito no Livro da Sabedoria que o Senhor, depois de haver modelado o primeiro ser humano, infundiu-lhe com um sopro algo que vence a morte: a alma.

E, se a criatura assim dotada tem a faculdade de usar, bem ou mal, dos dons que Deus lhe deu, que exemplos admiráveis nos oferecem aqueles que se erguem do pó, e lutam para não sossobrar sob o peso de condições ingratas, e se afirmam, e vencem.

E volta-nos à lembrança a sentença bíblica “pulvis es..." Sim. Eles eram pó. Mas, assim como o pó, suspenso nos raios solares, se irisa e resplandece, do mesmo modo,

*. Discurso proferido na sessão solene de instalação da Academia Paulista de Direito, na Faculdade de Direito da Universidade de São Paulo, no dia 11 de agosto de 1972. 
a pobre argila humana, tocada pelo espírito, se transmuda em chama que não se apaga, mesmo nos domínios da morte.

Veja-se a vida de José Antonio Pimenta Bueno. Nada consta sobre suas origens. Imprecisa é a data de seu nascimento. Seus biógrafos se desentendem quanto à cidade que lhe serviu de berço.

Sabemos apenas que, infante exposto, de paternidade ignorada, corações piedosos o acolheram, levaram-no à pia batismal, deram-lhe um nome e propiciaram-lhe condições para seguir o curso da Faculdade de Direito do Largo de São Francisco.

Não obstante os contratempos dos primeiros dias, JosÉ Antonio Pimenta Bueno conseguiu ser o artífice de uma grande vida: a sua própria vida.

Não vemos nele o herói providencial de Carlyle, preposto do destino para feitos extraordinários. Nem o herói dos contos fantásticos, que passa como um bólide fulgurante a subverter a harmonia estelar para perder-se em ocasos de púrpura.

José Antonio Pimenta Bueno apresenta-se-nos como o viandante de longa jornada, vencida a duras penas, passo a passo, em ascensão constante, que o levou de amanuense do Tesouro Provincial à dignidade de Marquês de São Vicente e Grande do Império.

E porque ele foi no consenso de um de seus biógrafos, "o maior jurista que São Paulo deu ao Brasil e um dos primeiros da nacionalidade" ${ }^{1}$ louvados sejam os responsáveis pela idéia de consagrá-lo como patrono da Academia Paulista de Direito. Homenagem não só justa, mas reparadora da permanente omissão de São Paulo de render a seu grande filho o tributo que ele bem merece.

1. Haroldo Valadão, Pimenta Bueno, Grande Publicista e Constitucionalista do Império, Jornal do Comercio, 29.8.1948, Rio de Janeiro. 
Que há em nossa cidade em memória do Marquês de São Vicente? - Alguma estátua? - Uma avenida? - Uma praça?

Há, parece, uma simples rua, perdida em bairro longinquo, nos confins da urbe.

Não é este o momento de dissertar sobre Pimenta Bueno. O tempo "meu inimigo", mas amigo da ilustre assistência, não mo permite.

Investido, porém, no encargo honrosíssimo de proferir o elogio do patrono de nossa Academia, não posso eximirme de evocar, embora de relance, os predicados mais característicos desse paulista insigne, que deixou a sua Província para fazer grandes coisas pelo Brasil.

Ele soube cumprir a vocação histórica de sua gente: "Pro Brasilia fiant eximia".

A partir dos primeiros meses do ano de 1828 , quem passasse pelo Largo de São Francisco haveria de estranhar a alacridade das vozes que ecoavam sob as velhas arcadas do convento ali existente.

Não se veja nessa evocação nenhum devaneio retórico, pois aqueles trinta e três moços que, há um século e meio, inauguraram esta Faculdade, deviam ser ("cela vasans dire") mais expansivos do que os frades. E presume-se que desde então, o silêncio fugiu das vetustas arcadas. É possível até que alguma beata ao acercar-se daqueles sítios, após suas orações matinais na igreja franciscana, se escandalizasse ao ouvir, em vez de preces e litanias, canções brejeiras ou ditos picarescos. E, sem dúvida, ela haveria de persignar-se com os esconjuros de seu breviário de orações, temerosa de que o diabo em pessoa andasse a bailar no velho claustro!

Pimenta Bueno pertenceu à primeira turma da recémcriada Faculdade.

Não sei se ele foi estudante folgazão ou retraído. Não sei se ele chegou até à gargalhada ou ficou no sorriso. Não 
sei se já êle se viciara no linguajar paulista, trocando os "r r" pelos "1 l".

Mais tarde, quando o nosso primeiranista se sentava numa poltrona do Senado Imperial, conta-nos MACHADO DE Assis, em Páginas Recolhidas, — que êle "ria com facilidade um riso bom."

E embora não tivesse conseguindo libertar-se do cacoete que adquirira de trocar os " $r$ " pelos " 1 ", ainda assim, falando na tribuna, "impunha silêncio, obrigava à atenção, dominava o auditório e firmava, confirmava e mantinha sempre sua reputação de parlamentar de primeira ordem. Era o triunfo mais esplêndido do poder da inteligência." São palavras tomadas a Joaquim Manoel DE MAcEdo, no seu Elogio Histórico.

Que ele foi estudante distinto, destacando-se entre os seus colegas, é fato inconteste.

Onze anos mais tarde em 1843, obtinha ele a laurea de doutor, com aprovação plena, "por sinal que a primeira concedida pela Faculdade de Direito de São Paulo", comenta Spencer Vampré 2 .

Registre-se que ao matricular-se Pimenta Bueno na Faculdade de Direito, já havia ele estreiado no jornalismo, em 1827, como redator do Farol Paulistano, o primeiro jornal impresso em São Paulo.

Pimenta Bueno ingressou na magistratura como juiz de fora e depois juiz de direito e chefe de polícia de Santos, juiz de direito da comarca do Paraná, desembargador dos tribunais de Relação do Maranhão e da Corte, onde oficiou durante dez anos, aposentando-se com a hierarquia de ministro do Supremo Tribunal de Justiça.

De sua alta compreensão dos atributos da magistratura, como órgão soberano da realização da justiça, dá-nos teste-

2. SPENCER VAMPRÉ, O Marquês de São Vicente, Revista Jurídica, vol. XI, n. ${ }^{\circ} 31$, julho de 1948, Rio de Janeiro. 
munho aquele episódio de seu encontro, quando juiz de Santos, com outro grande paulista, o padre Diogo Antonio FeIJó, senador do Império, então desterrados para a Província do Espírito Santo, por motivo de sua participação no movimento revolucionário de 1842.

FeIJó, inconformado com a medida do Governo, comunica ao juiz Pimenta Bueno o seu propósito de impetrar uma ordem de "habeas-corpus". E o jovem magistrado responde, de pronto, que não se negaria a conceder-lhe a ordem, em virtude da manifesta ilegalidade do ato que atentava contra as imunidades de um senador do Império.

Aquela corajosa manifestação de independência de um juiz, em face do Poder Executivo, nas circunstâncias politicas que agitavam a nação, comoveu o bravo lidador, que um dia saíu da paróquia de Itu para restaurar a ordem civil no Brasil. E Feisó disse a Pimenta Bueno: "Conheço de longa data a integridade de seu caráter. Sei que não hesitaria em conceder-me a ordem de "habeas-corpus", incorrendo nas iras do Ministro. Mas, desisto do recurso porque espero que se consume a violência do Governo para acusá-lo no Senado".

Eram dessa têmpera o senador Diogo Antonio Feijó e o juiz Pimenta Bueno. Um e outro podiam medir-se no mesmo altiplano de dignidade.

"Não menos ilustre se nos evidencia a carreira política de Pimenta Bueno - atesta-o Spencer Vampré - Presidente de Mato Grosso de 1835 a 1837. Ministro plenipotenciário no Paraguai de 1844 a 1846. Deputado geral por São Paulo em 1848. Ministro dos Estrangeiros e depois da Justiça em 1848, no Gabinete presidido pelo Visconde de Macahé. Presidente da Província do Rio Grande do Sul em 1850. Senador do Império em 1853. Organizador do gabinete de 29 de setembro de 1870, onde ocupou a pasta dos Estrangeiros, - - em todas as altas investiduras políticas deixou traços fúlgidos de sua dedicação à causa pública e de seus excepcionais talentos. 
O Imperador escolheu-o Senador do Império, de uma lista sextupla, oferecida pela Província de São Paulo. Além disso, distinguiu-o com os seguintes títulos. Oficial da Ordem da Rosa; Conselheiro de Estado Extraordinário, em agôsto de 1859; Conselheiro de Estado Ordinário, em 1866; Visconde de São Vicente, em 1867, e Marquês de São Vicente, em 1872" 3.

Quando, em 1844, os acontecimentos políticos do sul do continente reclamaram do Governo Imperial pessoa hábil para a defesa dos interesses do Brasil, ameaçados pelas pretensões hegemônicas de Rosas, o nome que se impôs, desde logo, como o indicado ao desempenho da difícil missão foi o de Pimenta Bueno.

Na qualidade de encarregado de negócios e consul-geral em Assunção, ao tempo do governo de Carlos Solano Lopez, Pimenta Bueno conseguiu o que ninguém podia supor: fazer-se ouvir e acatar pelo intratável ditador guarani, ao ponto de levá-lo a adotar medidas mais liberais, na política interna do país, segundo o testemunho de Demersay, na sua Histoire du Paraguay ${ }^{4}$.

O fato de Carlos Solano Lopez haver convidado Pimenta Bueno para padrinho de um de seus filhos é sobremodo expressivo.

Mas o feito maior do diplomata brasileiro, em face dos graves problemas com que ele se defrontou no Sul, foi o de haver provocado o malogro da pretensão de Rosas de constituir uma confederação, na qual o Paraguai formaria, como Estado satélite, sob a liderança da Argentina.

Os jornais de Buenos Aires ao profligar a conduta de Carlos Solano Lopez, "que se deixava guiar por uma potência estrangeira," prestavam, "malgré tout", significativa homenagem ao tino diplomático de Pimenta Bueno.

3. SPENCER VAMPRÉ, op. cit., pg. 10.

4. Demgrsay, op. cit., vol. II, pg. 437. 
De volta à pátria, Pimenta Bueno afirma-se como parlamentar, na Assembléia Geral e no Senado, durante vinte e dois anos, de 1848 a 1870.

Ouçamos, ainda uma vez, o testemunho de JosQurm Manoel de Macedo, no seu livro Elogio Histórico, anteriormente citado: "Na Câmara temporária e no Senado, primava como orador substancioso, lógico e de palavra sempre serena na tribuna parlamentar foi sempre orador doutrinário; em seus discursos nunca procurou mover paixões ou excitar entusiasmo; frio e reflletido, era mais conselheiro do que político de partido."

As qualidades de legislador e de estadista de Pimenta BuEno seriam reveladas, em grau eminente, no Conselho de Estado.

Basta enumerar dentre as tarefas de que ele se desincumbiu, no exercício de suas funções de Conselheiro, os projetos sôbre a emancipação dos escravos, a aberte do rio Amazonas, a reforma do Conselho de Estado e a Organização dos Conselhos das Presidências.

“Esses magnos problemas - pondera Spencer Vampré - cada um dos quais, bastante a encher de glórias uma existência, impunham-se ao espírito clarividente de Pimenta Bueno, e tão fecundos encontrava os argumentos, tão oportunas as soluções, que os próprios adversários, como Zacarias e Nabuco, não podiam eximir-se de discuti-los e a aceitá-los depois dos mais acalorados debates.

“Mas a iniciativa principal de São Vicente - continua SPENCER VAMpré - aquela que nunca se poderá apagar da memória dos brasileiros, é a relativa à emancipação dos escravos. Não se trata propriamente de um projeto, mas de cinco projetos, estreitamente ligados, e dos quais nasceu a Lei de 28 de setembro de 1871, também chamada "Lei Rio Branco" ou do "Ventre Livre" 5 .

5. SPENCER VAMPRE, op. cit., pgs. 13 e 14. 
No capítulo da abolição da escravatura, alguns nomes se apresentam aureolados pela fama, como figuras de primeira grandeza do movimento emancipador da raça negra no Brasil.

A imaginação popular os revê no palco da apoteose final do magno acontecimento histórico, ao lado da Princesa Isabel, a Redentora. Chamam-se eles Castro Alves, José do Patrocínio, Visconde do Rio Branco, Nabuco de Araujo. Bueno?

E D. Pedro II? - perguntará alguém. - E Pimenta

Estes são os grandes esquecidos.

JoAQUim NABUCO, fiel à verdade histórica, e sempre autêntico em seus pronunciamentos, atribui a D. Pedro a primazia do comando e da orientação da campanha emancipadora em nossa terra. Eis o seu juizo: "No primeiro plano do grupo própriamente dito de 1871, a figura central, sôbre cuja cabeça a vitória sustenta a coroa de ouro, como nos triunfos antigos, não deve ser Rio Branco, mas Dom Pedro II. Este nome, durante o reinado, a ficção constitucional mandava calar, mas a ficção já preencheu o seu fim, e a história, que não respeita ficções há de reconhecer nele o principal impulsor e o principal sustentáculo da reforma de 1871, levada a efeito por força derivada dele e a princípio transmitida por êle."

E Nabuco prossegue: "É nas suas mãos que está a chave da nossa política: é êle quem traça o roteiro da emancipação, servindo-se ora de um, ora de outro partido, captando para a idéia que tem em peito o ardor dos que lhe podem servir de apóstolos, como a tolerância e depois o consenso dos que, por um primeiro movimento a rejeitam; é êle quem emprega primeiro os liberais e depois os Conservadores; quem anima, quem não vê dificuldades, quem se não deixa aterrar nem demover; por últimos, mas acima de tudo, é êle o refém; 
é "seu" o maior interesse que está em causa: o trono que êle expõe sem medo, nesse grande pleito da humanidade" 6 .

Ai está, na palavra de NaBuco, uma verdade iniludivel, que só a ignorância pode desconhecer e a paixão política sofismar.

Nos pratos da balança em que se decidem os destinos dos povos ou as grandes causas da humanidade, nós temos visto capitães vitoriosos jogar a sua espada; mas de um rei que tivesse jogado a sua coroa, só sei, para glória do Brasil, daquele que se chamou D. Pedro II. E bastaria esse gesto para imortalizá-lo na consciência da nacionalidade.

No episódio da abolição, como em outros grandes acontecimentos históricos de que participou, durante o seu longo reinado D. Pedro II continua aguardando "a justiça de Deus na voz da história".

Quanto à ação proeminente de Pimenta Bueno no processo de elaboração da Lei de 28 de setembro de 1871 e na seqüência dos fatos que levariam à abolição da escravatura, ninguém mais capacitado para opinar do que JoAquim NabUco. Escutemos o seu precioso depoimento: "O mais importante assunto de que Pimenta Bueno se ocupa é, porém, a emancipação dos escravos; os seus projetos de 1866, rejeitados, como vimos, por Olinda, sob Zacarias, servirão de base no Conselho do Estado aos estudos profundos de que resultou o plano e o desenho, como se vai ver, da lei de 28 de setembro de $1871^{7}$

É ainda o preclaro autor de Um Estadista do Império quem nos esclarece que, embora Nabuco de Araujo tenha sido o verdadeiro "redator" da lei de 28 de setembro de

6. JoAquim Nabuco, Um Estadista do Império, t. II, pgs. 158 e 163, São Paulo, 1936.

7. JoAquim Nabuco, op. cit., pg. 14. 
1871, “o material não fôra dele:... êle o tomou dos projetos de. São Vicente" 8 .

Essa declaração de Joaquim Nabuco, se, de uma parte, acentua o valor da participação de Pimenta Bueno no trabalho de preparo dos documentos legais da abolição, de outra, evidencia a superioridade de espírito e a probidade de historiador do filho do Conselheiro Nabuco de Araujo, que, não obstante esse vínculo, soube reconhecer o quanto seu ilustre pai se valeu dos projetos do mestres paulista, na redação da Lei do Ventre Livre.

E diz mais Johquim Nabuco: "Com toda a probabilidade, sem São Vicente, o partido conservador teria sido hostil à reforma".

E, aludindo aos projetos, observa: "No primeiro projeto, que estabelecia a liberdade dos nascituros, Pimenta BuENo dava à mãe escrava a preferência sôbre o destino do filho recém-nascido;. : era o seu sistema, o que quer dizer que de todos os estadistas partidários da libertação do ventre, foi êle o que propôs o plano mais adiantado, a solução mais ampla, porque evitava a servidão do nascituro até os vinte anos" ".

Quando D. Pedro II confiou a Pimenta Bueno a formulação dos projetos de lei, precursores da abolição, êle escotheu o homem que lhe parecia ser o melhor indicado para a grave tarefa.

Estava também no pensamento do Imperador que a São Vicente e não a outrem devia caber a glória de apor a assinatura na lei de libertação dos nascituros. Dai o convite que lhe dirigiu para formar o Gabinete que sucederia ao de Itaborai.

Pimenta Bueno acudiu ao apelo do Soberano. Mas, homem pouco afeito à política de bastidores e incapaz de

\footnotetext{
8. JoAquim NabUCO, op. cit., pgs. 52 e 53.

9. JoAquim Nabuco, op. cit., pgs. 21, 163 e 164.
} 
condescender com certas práticas infringentes de seus princípios éticos, ele entendeu que a melhor maneira de contribuir para o êxito da reforma pretendida seria renunciar. E, sem mais delongas, comunicou ao Imperador sua intenção. Inconformado com o propósito de Pimenta Bueno, D. Pedro II lembrou-lhe a glória que lhe adviria se êle, São Vicente, como governo, conseguisse a aprovação da lei em benefício dos escravos. - "Senhor - contestou Pimenta Bueno glória maior terei como Cristão: a de não concorrer um só dia, um só instante, para prejudicar os direitos dos nascituros" ${ }^{10}$.

E deixou o governo com o desapego dos homens que sabem renunciar às posições, quando a consciência o exige.

Se Pimenta Bueno notabilizou-se como estadista, político, legislador e diplomata, seu título maior, entretanto, é o de jurista.

E o que, acima de tudo o singulariza e o engrandece no âmbito do direito brasileiro, são as suas virtudes de criador.

Não direi que antes dele o direito pátrio fosse absolutamente informe e vazio, como a terra antes do "Fiat". Mas, tudo que se relacionava aqui com as disciplinas de Ulpiano e de Cujacio tinha ressaibos de além-mar. Não obstante a nossa independência política, ainda continuávamos a prestar a nossa vassalagem à velha Europa, nas ciências, nas letras e nas artes e... até nos maus exemplos...

Éramos um povo jovem, que emergia de duras refregas para construir uma Pátria.

A terra era imensa. A gente, pouca. A tarefa hercúlea.

Mas a raça soube responder ao desafio do destino.

E São Paulo que já havia dado ao Brasil José Bonı́ácro, para ensinar um príncipe a nos abrir os caminhos da liberdade, São Paulo deu à nossa incipente cultura jurídica

10. Joaquim Nabuco, op. cit., pg. 132, "apud" notas do Dr. OlIVETRA BORGES. 
Pimenta Bueno, para tirar da "selva escura" dos praxistas reinóis os lineamentos de nosso direito.

Por certo, êle não foi um inventor, como nenhum jurista, em tempo algum, o foi.

$O$ direito não é uma composição química, forjada no cadinho dos laboratórios. $\mathrm{O}$ direito, como o conceituou o próprio Pimenta Bueno é uma "entidade real, porém moral ou abstrata".

Como entidade real, isto é, como um fato, o direito se manifesta através da consciência jurídica da nacionalidade, em cujas águas lustrais ele deve batizar-se para não crescer pagão.

O jurista, a exemplo dessas antenas sensibilíssimas, que captam sons inaudíveis, tem o dom de auscultar as vozes primárias, que traduzem os anseios da alma de um povo. Ausculta-os, analisa-os, interpreta-os, e procura dar-lhes consistência real, porque, enfim, elas expressam uma necessidade.

Ai se apresenta o direito, como entidade real, condicionado, porém, às circunstâncias mesológicas e sociológicas do seu "habitat". Mas, para que ele se converta em força atuante é mister traduzi-lo em normas escritas ou consuetudinárias.

Essa adequação do direito, entidade real, ao meio, o primeiro que a praticou entre nós foi Pimenta Bueno.

$E$ foi sob estas arcadas que ele se formou. Foi aqui que ele aprendeu a escrever a cartilha das primeiras letras do direito brasileiro.

Há, pois, razões legítimas para que esta Escola se orgulhe de seu grande filho.

Os trabalhos jurídicos de Pimenta Bueno datam de mais de um século. Para julgá-los, deve-se recuar no tempo e considerar os escassos recursos de que ele dispunha na sua época a fim de compor as obras que nos legou com a rubrica de seu nome. 
Entre essas obras, quatro principalmente, são apontadas como as mais expressivas de seus predicados de jurista: os Apontamentos sobre as Formalidades do Processo Civil, os Apontamentos sobre o Processo Criminal e sua Forma, o Direito Público Brasileiro e a Análise da Constituição do Império e o Direito Internacional Privado e aplicação de seus princípios com referência a leis particulares do Brasil.

Nas palavras de introdução aos Apontamentos sobre as Formalidades do Processo Civil, o próprio autor nos mostra quão precárias e confusas eram as fontes de que dispunha para compor o seu trabalho. Referindo-se ao processo civil, observava Pimenta Bueno: "seu estudo é árido e fatigante, e sua teoria entre nós muito pouco cultivada. Nossos praxistas limitam-se a indicar os resumidos e algumas vezes obscuros e incompletos preceitos das ordenações, ou certos julgados, estilos e opiniões, algumas delas controversas, sem desenvolver os princípios elementares desta parte da ciência jurídica, e muito menos as razões, fundamentais de suas diversas disposições. Um tal método de estudo, além de degradar a importância da matéria, assassina a inteligência e tende mui positiva e diretamente a embrutecê-la: é fazer da jurisprudência relativa a este transcendente ramo dos interesses públicos um verdadeiro e ininteligível hieroglífico."

Nesta altura, Pimenta Bueno dá a impressão de que o processo civil brasileiro daquele tempo repetia a quem dele se acercasse a intimativa da Esfinge do caminho de Tebas ao viajor incauto: "Decifra-me ou eu te devoro!"

Pois o mestre paulista não se intimidou: enfrentou o enigma processual brasileiro e não foi devorado. Antes, decifrou-o. E ofereceu para as estantas vazias de nossa biblioteca jurídica os seus Apontamos sobre as Formalidades do Processo Civil, trabalho que, no parecer de Haroldo ValaDÃo, "constitue pela agudeza e profundidade de conceitos, 
em forma resumida e cristalina, uma obra básica de nosso direito" 11 .

O trabalho Apontamentos sobre o Processo Criminal Brasileiro é reedição ampliada de Apontamentos sobre o Processo Criminal pelo Juri, publicado em 1849, antes de qualquer outro do mesmo gênero no Brasil.

Podemos dizer sem receio de contestação - afirma Spencer Vampre - que os Apontamentos sobre o Processo Criminal Brasileiro "constituem a obra mais completa sobre o assunto, ainda que recentemente João Mendes, e Galdino DE Srqueira o tenham tratado com proficiência. A obra de JoÃo MENDES se acentua por um caráter essencialmente histórico. A de Pimenta Bueno é um belo e nobre monumento harmônico em suas linhas arquitetônicas" ${ }^{12}$.

No pórtico de Direito Público Brasileiro e Análise da Constituiçẫo do Império, lê-se: "A la loi son empire, aux hommes leur dignité". E na "Introdução", Pimenta Bueno reitera sua fidelidade a dois princípios: ordem e liberdade.

Coerente com essa "convicção sincera e profunda", Pimenta Bueno, fosse como homem público ou jurista, nunca admitiu qualquer antítese entre a lei e dignidade da criatura humana, vale dizer, entre a ordem e a liberdade. Em sintese, ele foi sempre um homem urbano no sentido clássico do termo.

Dai o seu culto à justiça, expresso em palavras que evidenciam o seu profundo respeito a essa instituição, como se poderá ver destes excertos do Direito Público Brasileiro: "A inteligência das sociedades civilizadas, amestradas pelas luzes de dolorosas experiências, tem reconhecido profundamente que os direitos e relações individuais do homem, que

11. HAROLDO VALADÃo, op. cit., Jornal do Comercio, 29.8.1948, Rio de Janeiro.

12. SPencer VAmpré, op. cit., pgs. 20 e 21. 
esses bens, os mais caros e preciosos, não devem depender de uma vontade movel e descricionária, como pela natureza das coisas em grande parte é a vontade da autoridade executiva, e sim da justiça e proteção legal, fixa e estável.

São direitos que têm sua origem na natureza; que são atributos permanentes e inseparáveis da entidade moral do homem, e que não devem ser sacrificados, pois que nem mesmo o interesse coletivo exige tal sacrifício". ${ }^{13}$

Aqui, Pimenta Bueno proclama o primado da justiça sobre todos os interesses.

Já em Roma quando o espírito jurídico pairava mais alto do que os lábaros das legiões dos Césares, aquela máxima que mandava "dar a cada um o que é seu", "suumcuique tribuendi", se impunha a todos os interesses.

A independência da magistratura é condição elementar para a exata aplicação da justiça. Assim o entende Pimenta Bueno, ao escrever: "A independência da magistratura deve ser uma verdade não só de direito como de fato; é a mais firme garantia dos direitos e liberdades, tanto civis como políticas do cidadão; é o princípio tutelar que estabelece e anima a confiança dos povos na reta aplicação da justiça; é preciso que o povo veja e creia que ela realmente existe. Tirai a independência do poder judiciário, e vós lhe tirareis sua grandeza, sua força moral, sua dignidade, não tereis magistrados, sim comissários, instrumentos ou escravos de um outro poder" 14 .

Que Pimenta Bueno se referisse nesses termos ao Poder Judiciário não é de admirar. MontesQuieu, dois séculos antes, havia assinalado a magistratura, em L'Esprit des Lois, o predicativo de poder do Estado. E assim dispunha a Constituição do Império, ao incluir o Poder Judiciário entre os demais poderes políticos (art. 10), todos êles "expressões naturais e necessárias da Soberania Nacional.

13. Pimenta Bueno, op. cit., pgs. 328 e 329 .

14. Pimenta Bueno, op. cit., pg. 332. 
O que, porém, surpreende é o alto conceito de Pimenta sôbre o Ministério Público, numa época em que esta instituição era praticamente ignorada entre nós. De fato, nem a legislação imperial, nem os juristas pátrios daquele tempo haviam tomado conhecimento do Ministério Público, resultando daí a situação precária em que se encontrava esse órgão, sem assento nas leis e voz nos concílios governamentais.

Pimenta Bueno, com a sua larga visão de estadista "double" de jurista, foi o primeiro entre seus pares a reconhecer a necessidade e a importância do Ministério Público e a situá-lo convenientemente. E ele o diz, nestas palavras, até então inéditas entre nós: " $O$ Ministério Público é uma grande e útil instituição, é o braço direito da sociedade e do governo, é a sua vigilância e intervenção perante os tribunais de justiça" ${ }^{15}$.

Denunciando os defeitos dos sistemas processuais acusatório e,inquisitório, que atribuiam, respectivamente, a quaiquer do povo e ao juiz a iniciativa da ação penal, Pimenta BuEno entende que essa prerrogativa deve caber exclusivamente ao Ministério Público, único órgão competente para promover a aplicação da lei contra o infrator.

"O Ministério Público - escreveu êle - deve ser um guarda vigilante e energico da ordem pública e repressão dos delitos, por mais importantes que sejam os delinqüentes. As leis penais não têm vida senão pela ação dele - "leges ipsae nihil valeant, nisi actoris idoneâ voce munitoe. "16.

No entender de Pimenta Bueno, o Ministério Público, deve exercer vigilância sobre a ação dos agentes de polícia, "para que não seja omissa ou frouxa" ${ }^{17}$.

15. Pimenta Bueno, op. cit., pg. 382.

16. Pimenta Bueno, Apontamentos sobre o Processo Criminal Brasileiro, pg. 64, Rio de Janeiro, 1922.

17. Pimenta Bueno, Direito Público Brasileiro, pg. 386. 
Ninguém, por mais importante que seja, exceto o Imperador e os representantes diplomáticos de paises estrageiros, se exime à ação repressiva do Ministério Público, pela prática de crimes comuns. Nem os membros da familia imperial, ministros de Estado, conselheiros de Estado, senadores e deputados, durante a legislatura ${ }^{18}$.

Finalmente - diz ainda Pimenta Bueno - esta magistratura exerce uma inspecção útil sobre as prisões e sobre o melhoramento da legislação criminal em seus diversos ramos ${ }^{19}$.

Era de supor-se, à vista do exposto, que o Ministério Público estivesse em condições de bem desempenhar seus complexos encargos. Entretanto, assim não acontecia, conforme se lê nestes trechos do mesmo jurista: "Nosso ministério público, assim como quase todas as nossas instituições, por ora é incompleto, sem centro, sem ligação, sem unidade, inspecção e harmonia. Sofre de mais a mais lacunas graves nas atribuições, conferidas a seus agentes, lacunas que muito prejudicam a administração da justiça" ${ }^{20}$.

De tudo se conclui que, em se tratando de Ministério Público, ainda há o que aprender com o Marquês de São Vicente.

O Direito Público e Análise da Constituição do Império foi o primeiro tratado sistemático ide direito público e constitucional publicado entre nós, e não excedido quanto ao seu valor doutrinário - escreveu Haroldo Valadão.

"Na América Latina - continua o mesmo autor - também cabe a Pimenta Bueno, no Direito Público Constitucional, a prioridade que teve no Direito Internacional Privado.

18. Pimenta Bueno, op. cit. pg. 387.

19. Pimenta Bueno, op. cit., pg. 387.

20. Pimenta Bueno, Apontamentos sobre Processo Criminal Brasileiro, pg. 66 . 
E por isto, a sua grandiosa obra apresenta o sólido caráter de exposição criadora..." 21 .

Ai vemos a razão do alto elogio de Pontes de Miranda ao considerar Pimenta Bueno "o maior dos conhecedores do direito público no Brasil”.

É Pimenta Bueno quem nos revela, na Introdução do Direito Internacional Frivado, que ao tempo da publicação desse livro, em 1863, não havia "compêndio nem consultor nacional para esse estudo."

Sua modéstia não lhe permitiu dizer o que mais tarde atestariam seus biógrafos, isto é, que o seu trabalho "foi a primeira obra sistemática da matéria, editada no mundo ibero-americano modernamente. Nem na Espanha, nem em Portugal, nem na América Central ou América do Sul havia ainda aperecido qualquer trabalho doutrinário completo $\mathrm{e}$ metódico como aquele" 22 .

"Quando os ditames do direito são lúcidamente deduzidos a própria força se detém e para na presença dele”. São palavraś de Pimenta Bueno nas páginas de Introdução de seu livro Direito Internacional Privado.

"Utopia" - dirão os que vêem na tremenda realidade universal o desmentido daquele enunciado.

"Sublime utopia" - dirão os que ainda acreditam num mundo melhor.

Ninguém, entretanto, negará que aquela frase é a afirmação do nobre caráter de um alto espírito que se chamou José Antonro Pimenta Bueno, Marquês de São Vicente, Grande do Império e - vamos dizer - "Bandeirante do Direito Brasileiro".

21. Haroldo VALAdÃo, op. cit., Jornal do Comercio, 29.8.1948, Rio de Janeiro.

22. HAROLDO VALADÃO, op. oit., ibidem. 